\title{
Synchronous Adenocarcinomas of the Jejunum and Sigmoid Colon-A Rare Case
}

\author{
Nisar Ahmad Chowdri, Rayees Ahmad Dar, Munir Ahmad Wani, Fazl Qadir Parray \\ Department of General and Minimal Invasive Surgery, Sheri Kashmir Institute of Medical Sciences, \\ Srinagar, India \\ Email: dr.rayeesdar@gmail.com
}

Received 5 March 2014; revised 4 April 2014; accepted 5 May 2014

Copyright (C) 2014 by authors and Scientific Research Publishing Inc.

This work is licensed under the Creative Commons Attribution International License (CC BY).

http://creativecommons.org/licenses/by/4.0/

(c) (i) Open Access

\begin{abstract}
Primary adenocarcinomas of the small bowel are rare. Because of their rarity, non-specific symptoms and diagnostic difficulty, small bowel tumors are often diagnosed and treated late in their course. The diagnostic difficulty is increased when these tumors arise in association with primary synchronous tumors of the colon. We present a case of a 17-year-old female who was evaluated for anemia and bleeding per rectum. Colonoscopy revealed multiple colonic polyps. Intraoperatively, she was surprisingly found to be having a synchronous jejunal growth apart from multiple colonic polyoid lesions. Total colectomy was performed along with resection of jejunal growth. Histopathology of colonic specimen revealed multiple polypoid projections with one polyp showing adenocarcinoma and rest severe dysplasia. Histopathology of jejunal growth revealed poorly-differentiated adenocarcinoma. Very rarely, cases have been reported in literature, where the primary adenocarcinoma of the jejunum developed synchronously with colonic adenocarcinoma, and both treated surgically on the same occasion.
\end{abstract}

\section{Keywords}

Synchronous, Adenocarcinoma, Colon, Jejunum

\section{Introduction}

Although small bowel represents $75 \%$ of the length of the intestinal tract, primary adenocarcinomas of the small intestine are rare and malignant tumors of the small bowel account for less than $1 \%$ of the intestinal malignancies [1] [2]. When these tumors arise in association with primary synchronous tumors of the colon, the diagnostic difficulty is often increased. The incidence of synchronous adenocarcinomas of the large bowel ranges from $0.6 \%$ to $11 \%$ in the international literature. 


\section{Case Report}

A 17-year-old female presented to the out-patient clinic of our institute with chief complaints of occasional episodes of bleeding per rectum and intermittent constipation since last three years. There was no history of pain during defecation, mucus discharge, vomiting, loss of appetite, bleeding from any other orifice, and loss of weight. There was no similar history in other members of family. On general physical examination, she was grossly pale. There was no icterus, lymphadenopathy or any muco-cutaneous pigmentation. Pulse rate was 88 beats/minute and blood pressure was 120/80 mmHg. Systemic examination was grossly normal except for mild abdominal tenderness. Digital rectal examination and proctoscopy didn't reveal any pathology. Colonoscopy was advised which revealed multiple, large as well as small, polyps. Most of these were stalked with few sessile ones, mainly involving sigmoid colon, descending and transverse colon. Snare polypectomy of six stalked polyps was done and tissue sent for histopathological examination (HPE) which showed features of tubulo-villous adenoma. Upper gastrointestinal endoscopy was normal. Abdominal Ultrasonogram revealed no abnormalities. Patient was planned for surgical intervention. Her baseline investigations were normal except for her haemoglobin $(\mathrm{Hb})$ which was only $6.7 \mathrm{grams} / \mathrm{deciliter}(\mathrm{gm} / \mathrm{dl})$. She received blood transfusions and her $\mathrm{Hb}$ rose to 10 $\mathrm{gm} / \mathrm{dl}$. Exploratory laparotomy was performed under general anaesthesia. There were multiple polypoid lesions involving mainly sigmoid colon, descending and transverse colon (Figure 1(a)). Surprisingly, there was a 4 - 5 $\mathrm{cm}$ ulcero-proliferative growth in the jejunum breaching serosa (Figure 1(b)) and adherent to mesenteric vessels. Multiple enlarged ileo-colic lymph nodes were also present. However, there was no liver or pelvic metastasis. Total colectomy with end to side ileo-rectal anastomosis with resection of jejunal growth and duodeno-jejunal anastomosis was done. Patient was extubated and shifted to high dependency unit in the immediate post-operative period. She was shifted to general ward on second post-operative day, drains removed on fifth and seventh post-operative days and discharged on eighth post-operative day. HPE of specimen of colon showed multiple polypoid projections with one of the polyps (in sigmoid colon) showing features of adenocarcinoma whereas others showing extensive dysplasia. HPE of specimen of jejunum revealed poorly differentiated adenocarcinoma with trans-serosal infiltration. Tumor emboli were seen within lymphatics and vessels. Jejunal resection margins were free of tumor. However, lymph nodes removed were free of tumor. She received adjuvant chemotherapy and is on regular follow up. Other two siblings of the patient were also screened for gastrointestinal polyps, however, were negative for same. Genetic testing for adenomatous polyposis coli (APC) gene of first degree relatives was also negative.

\section{Discussion}

A rare case of synchronous small and large bowel adenocarcinoma in a young girl is presented. The rarity of the small bowel tumors and their non-specific symptomatology render their preoperative diagnosis difficult. The liquid contents of the small bowel, low bacterial counts, short transit time, alkaline $\mathrm{Ph}$ and high concentration of immunoglobulin IgA are some of the factors which might account for the low incidence of small bowel tumors [2].

The distribution of primary adenocarcinomas within the small intestine varies in different studies. Results of 1050 case reports collected by Reiner in 1976 show decreasing aboral gradient: 40\% duodenal, 38\% jejunal, 22\% ileal [3]. Adenocarcinoma is the most common type of small bowel cancer, constituting $32 \%-54 \%$ of all

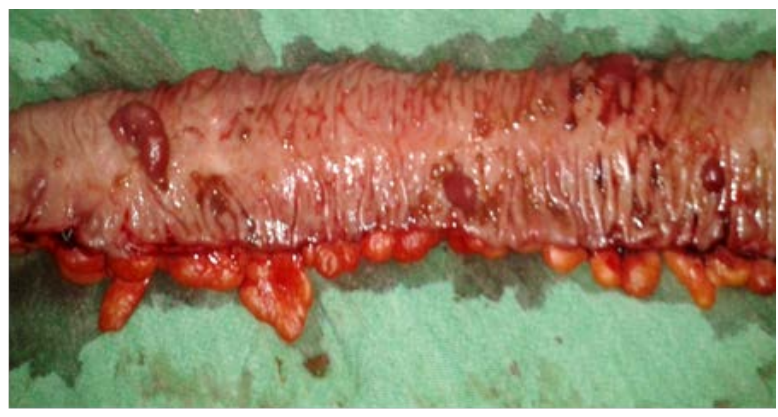

(a)

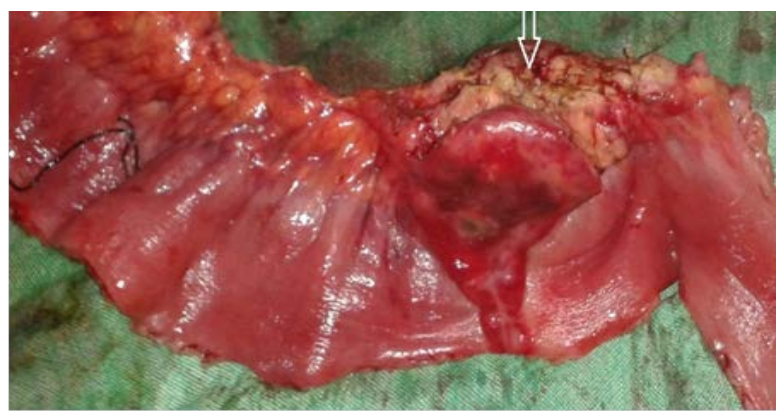

(b)

Figure 1. (a) Multiple polypoidal lesions in colon; (b) Ulcero-proliferative growth in jejunum. 
malignant enteric tumors [4]. Ouiriel and Adams [5] reviewed a series of 65 patients with adenocarcinoma of the small intestine and found that associated malignancies were present in 16 patients (25\%), the malignancy being colonic adenocarcinoma in 12 patients. There is a high frequency of secondary synchronous and metachronous neoplasms associated with small intestinal carcinoma [6]. However, they are often misdiagnosed as metastatic or recurrent colonic carcinomas when present in association with a colorectal carcinoma. Another possible causal factor of synchronous small and large bowel carcinomas is thought to be therapeutic irradiation, subsequent to bowel malignancy [7].

Familial adenomatous polyposis (FAP) was ruled out in our patient as there was no family history of similar disease and screening of other family members was negative. Very rarely a case of synchronous primary adenocarcinomas-involving the large bowel (Sigmoid) and the jejunum has been described before. The surgeon should always be alert for the possibility of multiple malignancies in the abdomen during laparotomies. Radical resection and lymphadenectomy are the only way to prolong the patient's life. In this case we added adjuvant chemotherapy in the hope of improving prognosis and survival. When two synchronous carcinomas in the large bowel are detected, we suggest that the small bowel should also be investigated with enteroscopy. First degree relatives of the patient should also be screened for similar lesions. The prognosis of synchronous primary adenocarcinomas of the large and small bowel correlates better with the depth of invasion, tumor size and lymph node metastasis

\section{References}

[1] Langevin, J.M. and Nivatongs, S. (1984) The True Incidence of Synchronous Cancer of the large Bowel. A Prospective Study. The American Journal of Surgery, 330, 147-151.

[2] Lowelfels, A.B. (1973) Why Are Small Bowel Tumors So Rare? Lancet, 1, 24-29. http://dx.doi.org/10.1016/S0140-6736(73)91228-2

[3] Reiner, M.A. (1976) Primary Malignant Neoplasms of the Smallbowel. Mount Sinai Journal of Medicine, 43, $274-280$.

[4] Treadwell, T.A. and White, R.R. (1975) Primary Tumors of the Smallbowel. The American Journal of Surgery, 130, 749-755. http://dx.doi.org/10.1016/0002-9610(75)90435-3

[5] Ouriel, K. and Adams, J.T. (1984) Adenocarcinoma of the Small Intestine. The American Journal of Surgery, 147, 66-71. http://dx.doi.org/10.1016/0002-9610(84)90036-9

[6] Alexander, J.W. and Altemeier, W.A. (1986) Association of Primary Neoplasms of the Small Intestine with Other Neoplastic Growths. Annals of Surgery, 167, 938-964.

[7] Gajraj, H., Davies, D.R. and Jackson, B.T. (1988) Synchronous Small and Large Bowel Cancer Developing after Pelvic Irradiation. Gut, 29, 126-128. http://dx.doi.org/10.1136/gut.29.1.126 
Scientific Research Publishing (SCIRP) is one of the largest Open Access journal publishers. It is currently publishing more than 200 open access, online, peer-reviewed journals covering a wide range of academic disciplines. SCIRP serves the worldwide academic communities and contributes to the progress and application of science with its publication.

Other selected journals from SCIRP are listed as below. Submit your manuscript to us via either submit@scirp.org or Online Submission Portal.
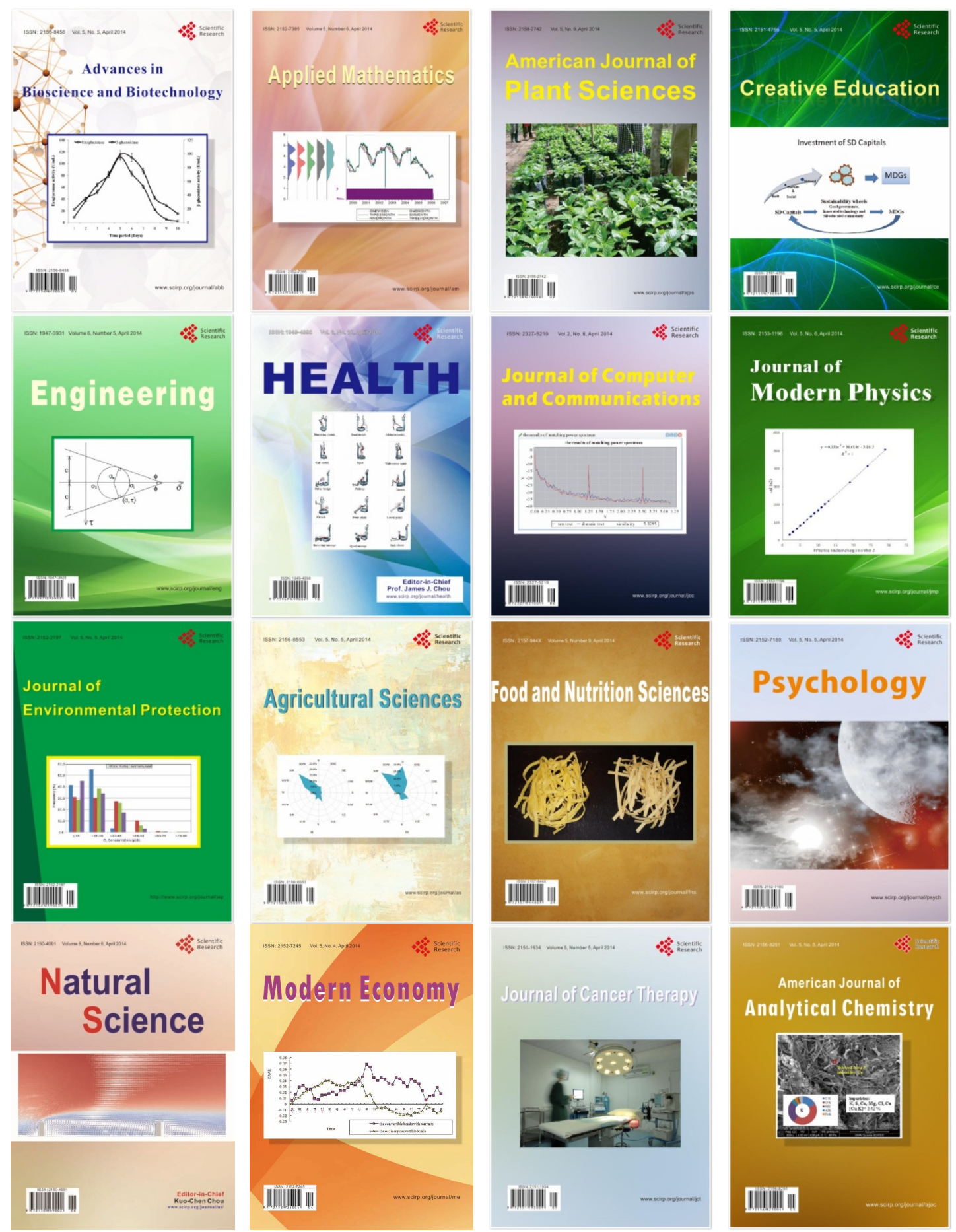